\title{
O Fenômeno de Muitas-Faces: Investigações Preliminares
}

\author{
Maria Lúcia de Bustamante Simas ${ }^{12}$ \\ Universidade Federal de Pernambuco \\ Natanael Antonio dos Santos \\ Universidade Federal da Paraíba
}

\begin{abstract}
Resumo
O fenômeno de muitas-faces foi investigado inicialmente no ponto cego e com faces familiares. Analizamos este efeito em 4 categorias: 1 ) desaparecimente/ escurecimento/ clareamento de partes da face; 2) variação de tamanho das partes da face; 3) percepção de movimento/ mudanças de expressão da face; 4) percepção de outras faces. Categorias 1 e 2 refletem impressões iniciais. Apenas relatos caindo nas categorias 3 e/ou 4 mostram o fenômeno. Os resultados fazem a análise de dados de 37 participantes utilizando fotografias da mãe, do pai e/ou parentes. A análise entre os participantes apresentou a incidência de $87 \%$ e $68 \%$ nas categorias 3 e 4, respectivamente. Na categoria 3, mudanças na expressão facial ocorreram $90 \%$ e $82 \%$ para mãe e pai, respectivamente. Na categoria 4 , o muitas-faces foi observado com maior freqüência na face da mãe $(73 \% ; n=30)$ do que na do pai $(41 \% ; n=22)$. Avaliamos estes resultados em termos de processamento periférico da forma considerando a possibilidade de haver uma sintonia para faces com base na freqüência de observação de uma mesma face durante o desenvolvimento na primeira infância.

Palavras-chave: Adaptação visual; adaptação a faces; percepção de faces; fenômeno de muitas-faces; freqüência espacial.
\end{abstract}

\section{The Multiple-faces Effect: Preliminary Studies}

\begin{abstract}
The multiple-faces effect was first investigated at the blind spot using familiar faces. We analyzed the effect into 4 categories: 1) disappearance/ darkening/whitening of face parts; 2) variation in size of face parts; 3) perception of movement / change in facial expression; 4) perception of other faces. Categories 1 and 2 reflect initial impressions. Only reports falling into categories 3 and/or 4 show the multiple-faces effect. Results analyzed data from 37 subjects (using mother and/or father and/or other relatives' photographs). Analysis across subjects yielded $87 \%$ and $68 \%$ in categories 3 and 4 , respectively. In category 3, changes in facial expression were $90 \%$ and $82 \%$ for mother and father faces, respectively. In category 4 , other faces were more frequently observed with the mother's face (73\%) than the father's (41\%) face. We discuss these results in terms of peripheral processing of form considering a possible tuning for faces resulting from frequency of viewing the same face during early visual development.

Keywords: Visual adaptation; face adaptation; face perception; multiple-faces effect; spatial frequency.
\end{abstract}

No decorrer de nossas pesquisas sobre filtros de freqüências espaciais, radiais e angulares (Simas, 1996), observamos um novo fenômeno envolvendo a percepção de faces. Tal fenômeno, relatado em Simas (2000), é ainda inédito na literatura nacional e pouco difundido na internacional. Quando uma face familiar medindo entre 21-25 graus de ângulo visual é apresentada de tal forma que seu nariz coincida com o ponto cego, são criadas as melhores condições de se observar uma série de eventos de interpolação pelo sistema visual humano, incluindo o fenômeno de muitas-faces. Na observação do "muitas-faces", os sujeitos relatam eventos que podem variar de algumas mudanças sutis nas expressões faciais quando comparadas à face impressa apresentada, até eventos onde faces diferentes (de outras identidades) são vistas se sobrepondo à face original. Estas outras faces são freqüentemente não-reconhecidas.

Ao constatar a presença do fenômeno, começamos uma investigação com 25 participantes (homens e mulheres) com faixa etária de 7-77 anos. Vinte e um destes (i.e., 84\%) narraram eventos

\footnotetext{
${ }^{1}$ Endereço para correspondência: LabVis-UFPE, Departamento de Psicologia, $\mathrm{CFCH} 9^{\circ}$ andar, Universidade Federal de Pernambuco, Recife, 50670 901. E-mail: maria.simas@ufpe.br\&mldbs@uol.com.br

${ }^{2}$ Agradecimentos: Ao CNPq e a FACEPE (processo APQ 0606-7.07/97) pelo apoio financeiro, e a todos os participantes da pesquisa.
}

relacionados ao muitas-faces (resultados não-publicados). Prosseguimos, portanto, para uma coleta de dados com outros 25 participantes ingênuos utilizando registros em áudio $(n=14)$ ou vídeo $(n=11)$. Neste estudo piloto observamos ser muito mais fácil obter o relato do "muitas-faces" quando as faces eram mais familiares aos participantes Em conseqüência, começamos a solicitar de cada voluntário fotos dos pais ou irmãos/irmãs, etc. Digitalizamos cada foto (geralmente $3 \times 4$ ou passaporte), aumentamos seu tamanho para as medidas apropriadas e convertemos para preto e branco. Os arquivos das fotos geradas foram impressos em papel comum. A montagem da foto-estímulo consistiu em se colocar um círculo preto no nariz e marcar dois pontos de fixação em cada lado da face para que as fotos fossem observadas a uma distância aproximada de 25$30 \mathrm{~cm}$ (ver Figura1). O voluntário foi instruído a fechar um dos olhos (sem pressionar) e a olhar fixamente para um dos pontos laterais, dependendo do olho que permanecesse aberto, e a mover o estímulo para frente ou para trás até encontrar a distância em que o círculo preto do nariz desaparecesse. Era pedido ao participante que, ao mesmo tempo em que mantivesse a fixação no ponto indicado, narrasse quaisquer alterações, mesmo que ocorressem muito rápido. O procedimento era feito com cada olho separadamente. Os voluntários tipicamente narravam desaparecimentos aleatórios do nariz, um ou dois olhos, boca, cabelo, meia-face, etc. Aumento 
do tamanho dos olhos e da boca foi relatado várias vezes. Todos estes eventos poderiam ocorrer na ausência do fenômeno de muitasfaces. A observação do fenômeno foi coincidente, muitas vezes, com alguma manifestação emocional tal como, um sorriso, uma exclamação, uma gargalhada ou reação de surpresa. O tempo para observação do muitas-faces varia bastante de um participante para outro, assim como de uma apresentação para outra, e depende se o participante já viu o efeito anteriormente. Dos 25 voluntários, 18 (i.e., $72 \%$ ) narraram eventos que foram consistentes com a ocorrência do "muitas-faces" (resultados não-publicados).

O presente trabalho ampliou a amostra de registros em vídeo e apresenta um sistema de classificação das narrativas desenvolvido por nós com base nos estudos anteriores. Passamos a solicitar aos voluntários fotos de ambos os pais (sempre que possível) e classificamos eventos narrados por um sujeito com ambas fotos como apenas uma ocorrência nas determinadas categorias.

Observações de participantes que relataram o fenômeno nos levaram a constatar que o "muitas-faces" poderia não ser específico ao ponto cego. Portanto, narramos também aqui um experimento piloto feito com alguns participantes não-ingênuos na região periférica contra-lateral ao ponto cego.

\section{Método}

\section{Participantes}

Experimentos no ponto cego

Trinta e sete (37) voluntários ingênuos com idades entre 14 e 46 anos; 33 do sexo feminino e 4 do sexo masculino participaram deste experimento. Os participantes tinham acuidade visual normal ou corrigida e, na sua maioria, eram alunos do curso de graduação em psicologia da UFPE.

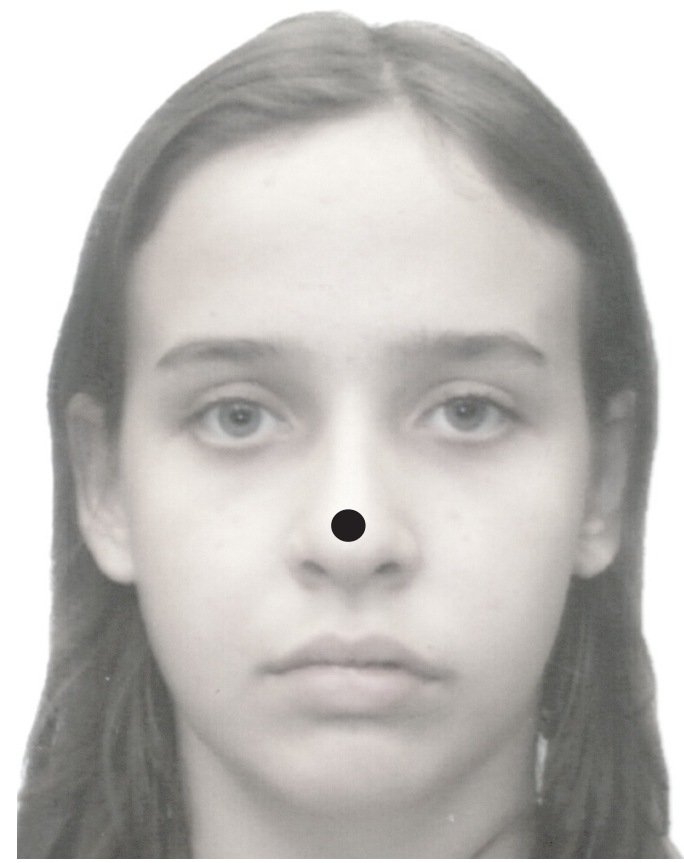

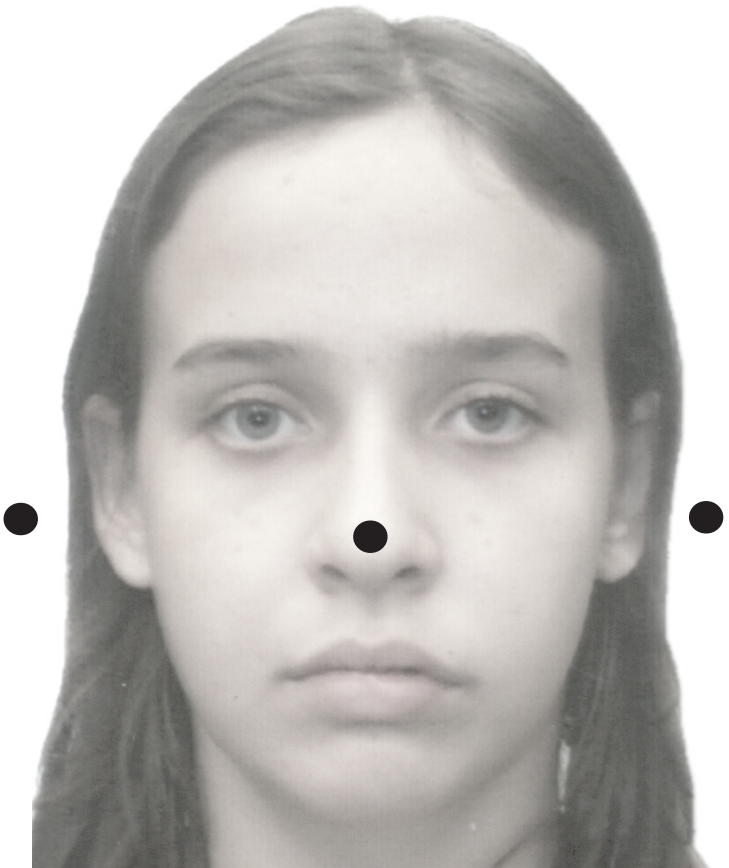

Figura 1. Exemplo de face-estímulo para investigação do fenômeno de muitas-faces no ponto cego. Para ver o fenômeno, feche o olho direito e focalize o ponto preto à direita da imagem. Varie a distância (no máximo a $30 \mathrm{~cm}$ ) e pare quando o ponto do nariz desaparecer. Mantenha a fixação e veja o efeito. Faça o oposto para observar com o olho esquerdo.

\section{Experimentos piloto na região contra-lateral ao ponto cego}

Nove (9) voluntários não-ingênuos com idades entre 20 e 27 anos; 8 do sexo feminino e 1 do masculino participaram do experimento. Os participantes tinham acuidade visual normal ou corrigida e eram alunos do curso de graduação em psicologia da UFPE.

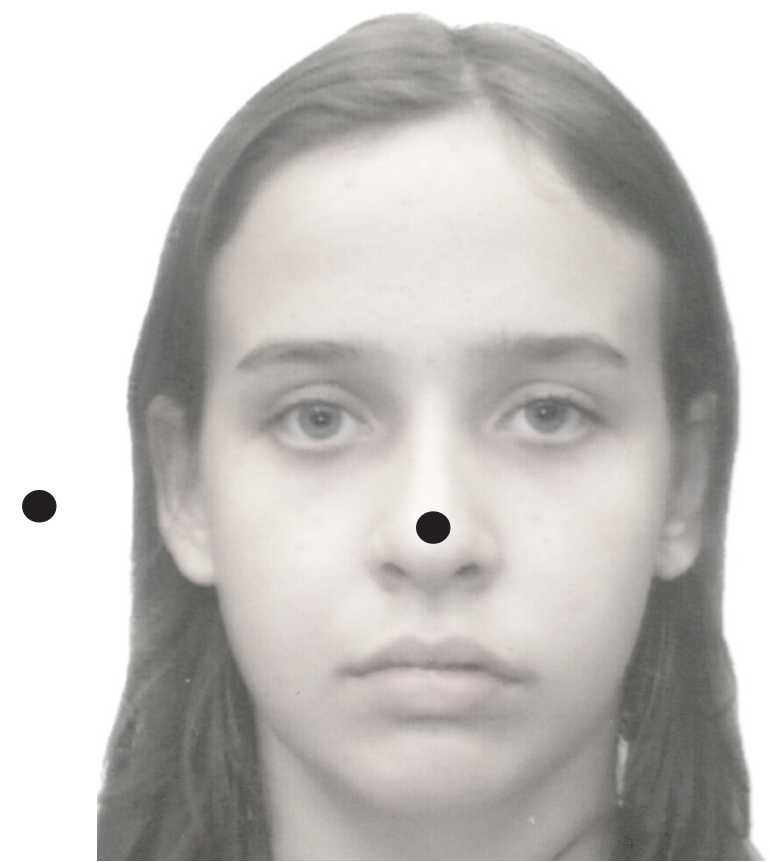

Figura 2. Faces-estímulo para observação do fenômeno de muitas-faces no lado contralateral ao ponto cego. O ponto de fixação é sempre o do centro. Por exemplo, com o olho direito fechado fixe o ponto central e mova o papel para frente ou para trás até o ponto preto da imagem à esquerda desaparecer. Mantenha esta distância e observe o fenômeno na face onde o ponto preto permanece, i.e., a face à direita. 


\section{Material e equipamentos}

\section{Experimentos no ponto cego}

Neste estudo solicitamos mais especificamente por fotos somente da mãe e/ou do pai e, preferivelmente, de ambos. Após digitalizar com zoom em um scanner Deskscan HP6100c, ampliamos e imprimimos as fotos acromáticas na Deskjet-890c. Os rostos do queixo à testa mediam entre 21-25 graus de ângulo visual. A Figura 1 mostra um exemplo deste estímulo.

\section{Experimentos piloto na região contra-lateral ao ponto cego}

Neste caso, o estímulo, diferente do estudo no ponto cego, consistia em uma página com duas fotos iguais acromáticas colocadas lado a lado, com um ponto de fixação entre as fotos e com círculos pretos nos narizes das duas faces idênticas. Um exemplo deste tipo de estímulo está apresentado na Figura 2. As sessões experimentais foram registradas em vídeo.

\section{Procedimentos}

Experimentos no ponto cego

Conforme descrito anteriormente, nosso procedimento consistiu em colocar um círculo preto ( $\sim \mathrm{cm}$ de diâmetro) no nariz e marcar um ponto de fixação à direita e à esquerda da face. $\mathrm{O}$ participante fixa o ponto indicado (cada olho separadamente, por exemplo, fechando o olho direito, focaliza no ponto de fixação à esquerda) movimentando o estímulo para frente e para trás até desaparecer o círculo do nariz. A partir de então, mantém a fixação enquanto narra em voz alta suas observações. A única instrução fornecida foi que o participante relatasse o melhor possível o que estava acontecendo com a imagem visualizada, mesmo que o que visse ocorresse muito rapidamente.

\section{Experimentos piloto na região contra-lateral ao ponto cego}

O procedimento consistiu em colocar um círculo preto $(\sim 1 \mathrm{~cm}$ de diâmetro) no nariz de cada face e marcar um ponto de fixação entre as duas faces. O participante fixa o ponto central (cada olho separadamente) novamente movimentando o estímulo até desaparecer o círculo do nariz na região do ponto cego e mantém a fixação enquanto narra em voz alta suas observações da face contralateral ao ponto cego (que permanece com o ponto preto do nariz visível). Como anteriormente, a única instrução apresentada foi que o participante relatasse o melhor possível o que estivesse acontecendo com a imagem visualizada, mesmo que o que visse ocorresse muito rapidamente.

\section{Resultados}

Os resultados foram classificados por 6-10 observadores independentes nas 4 categorias que desenvolvemos com base nos estudos pilotos. Estas foram: 1) desaparecimento, escurecimento/ clareamento (olhos, nariz, boca, face, face nasal, face temporal, cabelo); 2) variação de tamanho (olhos, nariz, boca, face, face nasal, face temporal, cabelo); 3) percepção de movimento/mudança de expressão facial (olhos, boca, face, sobrancelha, 3D); e 4) surgimento de características diferentes ou outras faces (cabeça para baixo, vê a si mesmo, vê mais jovem, vê mais velho, surgimento de dentes, bigode/ barba, mudança de cabelo, vê perfil, outras faces).

Histogramas dos resultados por categoria e subcategorias estão apresentados nas Figuras 3, 4 e 5. As porcentagens estão ajustadas para o " $n$ " de cada amostra.
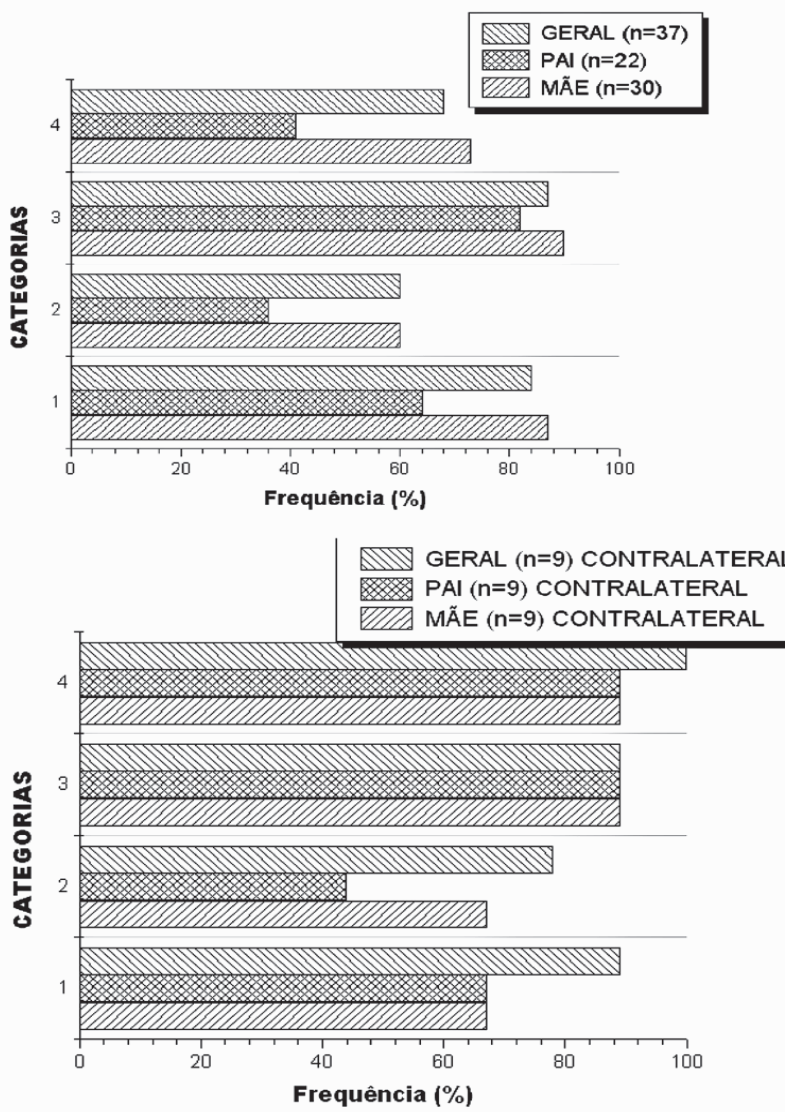

Figura 3. Porcentagens de ocorrência do fenômeno de muitas-faces com fotos do pai e da mãe nas condições no ponto cego e contralateral ao ponto cego. A categoria "Geral” reúne as condições mãe e pai.
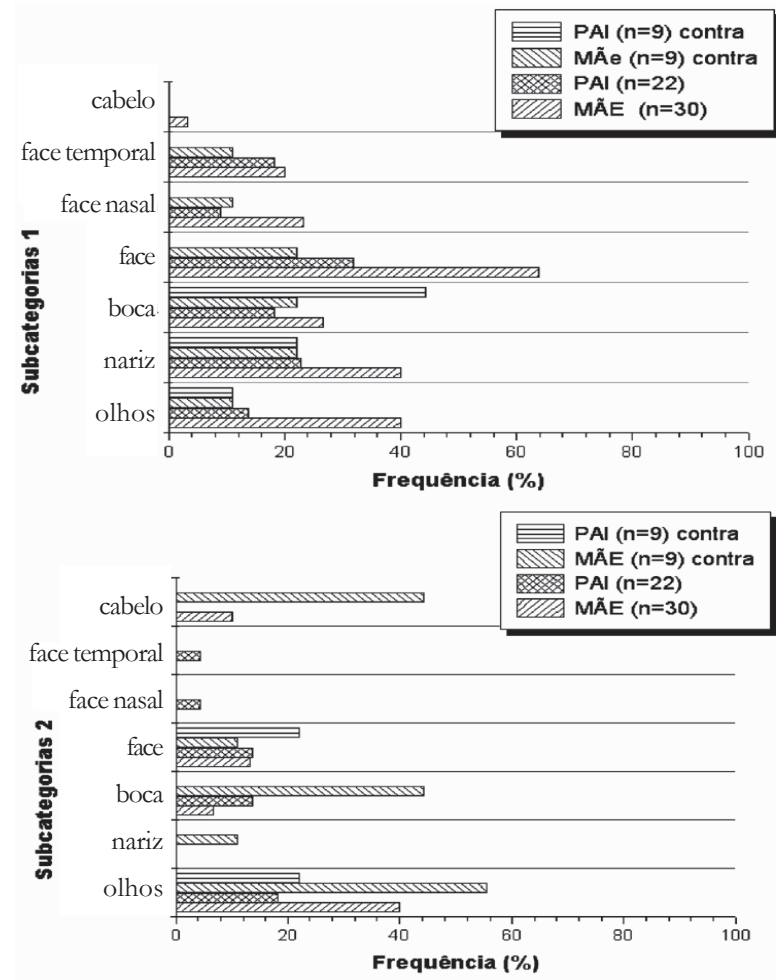

Figura 4. Porcentagens de ocorrência nas subcategorias 1 e 2 . As condições no ponto cego e contralateral ao ponto cego são comparadas para mãe e pai.

Psicologia: Reflexão e Crítica, 2005, 18(1), pp.104-108 


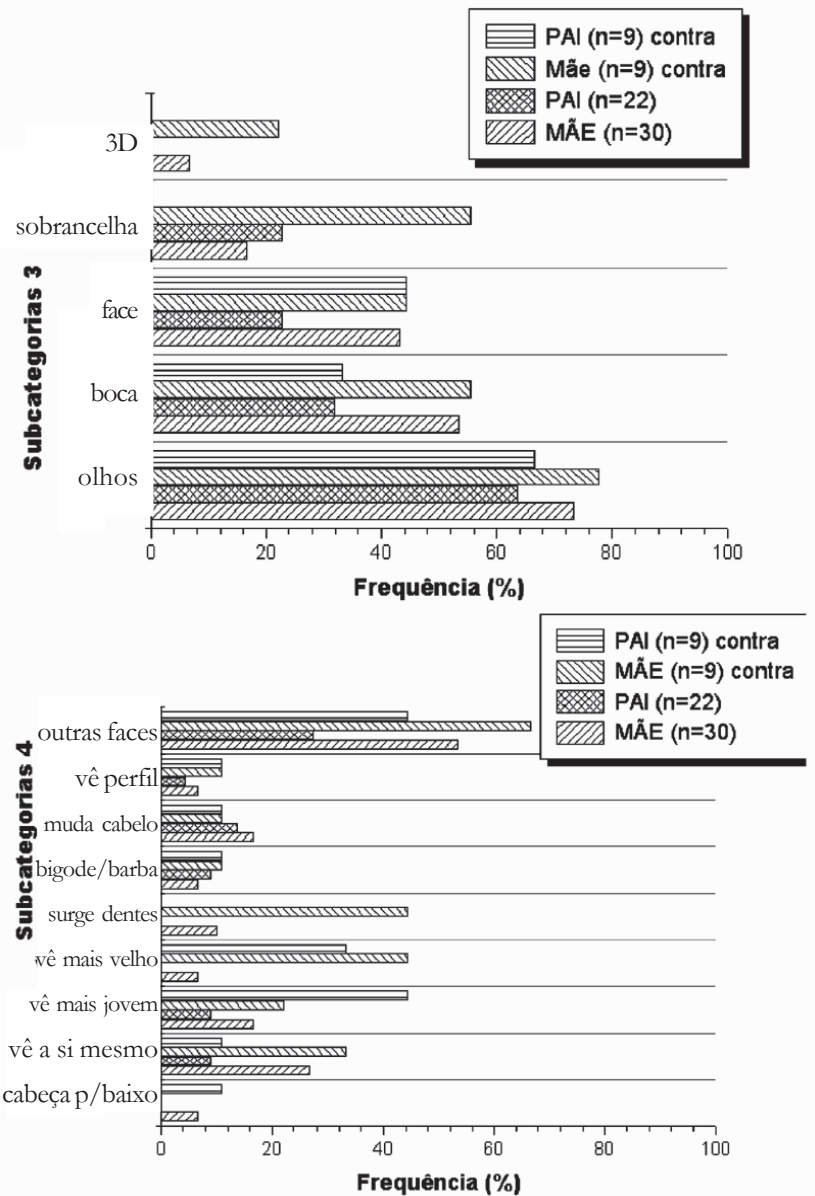

Figura 5. Porcentagens de ocorrência do fenômeno de muitas-faces nas subcategorias 3 e 4 . As condições no ponto cego e contralateral são comparadas para mãe e pai.

\section{Experimentos no ponto cego}

Os resultados após o acordo da maioria dos observadores para todos os participantes $(n=37)$ foram $84 \%, 60 \%$, 87\% e $68 \%$ para as categorias 1, 2, 3 e 4, respectivamente. Todos os efeitos ocorreram com maior freqüência nas fotos da mãe $(n=30), 87 \%$, $60 \%, 90 \%$ e $73 \%$, respectivamente, comparados com as do pai $(n=22), 64 \%, 36 \%, 82 \%$ e $41 \%$.

\section{Experimentos piloto na região contra-lateral ao ponto cego}

A porcentagem total para as categorias 1, 2, 3 e 4 foram: $67 \%, 67 \%$, 89\% e $89 \%$ para mãe e $67 \%, 44 \%, 89 \%$ e $89 \%$ para pai, respectivamente. Se consideramos as classificações 3 e 4 juntas, as porcentagens sobem para 89\% (mãe) e 100\% (pai).

\section{Incidência}

A primeira categoria, que não revela a presença do fenômeno, provavelmente está relacionada ao efeito de desaparecimento de Troxler (Troxler, 1804, citado em Mennemeir \& cols., 1994) onde desaparecimentos na periferia do campo visual podem ocorrer enquanto se olha fixamente para um ponto no espaço. Os eventos na segunda categoria ocorrem com freqüência e parecem relacionados às distorções na imagem percebida. Não revelam a presença do fenômeno. Por outro lado, a distribuição do fenômeno de muitas-faces nas subcategorias 3, mostra maior incidência de movimentos e/ou mudança de expressão facial nos olhos, na boca e na face toda. Já a distribuição do "muitasfaces" nas subcategorias 4 mostra que a percepção de outras faces (i.e., pelo menos duas outras faces diferentes da face estímulo) ocorre com quase o dobro da freqüência para a imagem estímulo da mãe. É também com a foto da mãe que ocorre maior incidência nas subcategorias "vê a si mesmo", "vê mais jovem", "vê mais velho" e "surge dentes" (i.e., sorriso com dentes), "vê outras faces".

\section{Discussão}

\section{Experimentos no ponto cego}

Embora a incidência da categoria 3 seja a mesma para fotos da mãe e do pai, esta incidência na categoria 4 para os pais cai para quase a metade em relação à da mãe. Este fato parece apontar para uma de nossas hipóteses de que o "muitas-faces" é fundamentado em faces extremamente familiares cuja freqüência de observação cumulativa excede as demais faces.

\section{Experimentos piloto na região contra-lateral ao ponto cego}

Conforme o esperado com base nos relatos iniciais de participantes submetidos ao experimento, o fenômeno de muitasfaces também ocorre em áreas periféricas fora do ponto cego. Até o momento não observamos diferenças entre as incidências com as fotos da mãe e do pai observadas na região contra-lateral ao ponto cego. Utilizamos um grupo pequeno de participantes não-ingênuos porque não sabíamos sobre a facilidade/ dificuldade de mensurar o fenômeno em regiões periféricas. Observamos, entretanto que, mais de um participante que não havia observado outras faces no ponto cego, as observaram na região contra-lateral.

\section{Aspectos gerais e teóricos do fenômeno}

No decorrer destes experimentos verificamos várias características a serem melhor investigadas: $O$ fenômeno de muitas-faces parece ser observado mais facilmente se: 1 ) as faces são bastante familiares; 2) é centrado no ponto cego; 3) o estímulo for acromático; 4) as faces variarem de 15 a 25 graus de ângulo visual; e 5) se os níveis de contraste forem médios. Geralmente ele ocorre em "trens de flashes", é muito rápido, pode incluir uma expressão emocional, pode envolver um grande número de faces não reconhecidas, e geralmente tende a ser observado após um período de 20-60s com participantes que o observam pela primeira vez. Além disso, ele parece ser mais específico para faces humanas em comparação com faces de macacos. Pequenos movimentos dos olhos (micro-sacádicos) podem ocorrer concomitantes à observação do "muitas-faces".

Por outro lado, sabemos que o reconhecimento de faces é dependente do gênero do observador (Ex.: Lewin \& Herlitz, 2002). Lewin e Herlitz observaram que não havia diferença entre 
homens e mulheres no reconhecimento de faces masculinas, porém, mulheres reconhecem melhor faces femininas. Entretanto, o fenômeno de muitas-faces não envolve necessariamente $o$ reconhecimento de faces, embora possa ocorrer. Ademais, durante os estudos anteriores, não observamos diferença de gênero assim como de lateralidade, i.e., preferência de processamento pelo hemisfério direito ou esquerdo. Quanto a esta última, nosso trabalho parece estar em concordância com os resultados de Kampf, Nachson e Babkoff (2002) que não encontraram lateralidade no reconhecimento de faces familiares. Porém, estes aspectos devem ser melhor estudados.

O fenômeno de muitas faces parece estar relacionado mais especificamente a uma adaptação a faces muito familiares e, à medida que o efeito de adaptação ocorre, outras faces relacionadas ao mesmo mecanismo de memória são percebidas (se sobrepondo a face indutora do efeito). Este mecanismo parece agir inicialmente em aspectos localizados e internos da face como, por exemplo, nos olhos, boca, nariz, bigode, etc. (mecanismos mais relacionados à nossa categoria 3) e, mais tarde, parece agir nos aspectos globais e de contorno da face tais como cabelo, barba, etc. (mecanismos mais relacionados à nossa categoria 4). Na literatura especializada só encontramos estudos de adaptação a faces distorcidas (MacLin \& Webster, 2001; Webster \& MacLin, 1999;) e nenhum estudo sobre adaptação a faces em proporções normais ou naturais. Escolhemos basear nossa hipótese principal em estudos fisiológicos que identificaram, no córtex ínfero-temporal de macacos, células que respondem a faces de sua própria espécie, assim como outras que respondem a perfis, e outros elementos da face (para uma revisão, ver Desimone, 1991). Nós supomos que estes mecanismos para detecção e identificação de faces existem e que são preliminarmente sintonizados muito cedo na infância para faces vistas com maior freqüência (i.e., geralmente a face da mãe ou da principal pessoa a cuidar do infante) e, mais tarde, à medida que outras faces são detectadas e arquivadas, estes mecanismos constroem memórias baseadas nas faces vistas mais freqüentemente e já armazenadas previamente (mais similares?), ou abrem novas matrizes para outras faces. Esta suposição tem apoio da literatura no trabalho de Quinn e colaboradores (Quinn, Yarh, Kuhn, Slater \& Pascalils, 2002) que afirma que a preferência por faces femininas pode ser influenciada pelo gênero da principal pessoa a cuidar do infante. Além disso, estes autores verificaram que quando a pessoa a cuidar do infante é do sexo masculino, a preferência muda para faces deste sexo. Entretanto, com base nos nossos resultados até o presente, o fenômeno de muitas faces não está muito claro com respeito ao gênero da face observada, pois faces masculinas foram observadas em fotos de faces femininas e vice-versa. Ainda estamos conduzindo experimentos em condições cada vez mais controladas para ampliar o nosso conhecimento sobre a ocorrência e as características deste fenômeno.

\section{Referências}

Desimone, R. (1991). Face-selective cells in the temporal cortex of monkeys. Journal of Cognitive Neuroscience, 3, 1-8.

Kampf, M., Nachson, I. \& Babkoff, H. (2002). A serial test of the laterality of familiar face recognition. Brain and Cognition, 50, 35-50.

Lewin, C. \& Herlitz, A. (2002). Sex differences in face recognition-Women's faces makes the difference. Brain and Cognition, 50, 121-128.

MacLin, O. H. \& Webster, M. A. (2001). Influence of adaptation on the perception of distortions in natural images. Journal of Electronic Imaging, 10, 100-109.

Mennemeir, M. S., Chatterjee, A., Watson, R. T., Wertman, E., Carter, L. P. \& Heilman, K. M. (1994). Contributions of the parietal and frontal lobes to sustained attention and habituation. Neuropsychologia, 32, 703-716.

Quinn, P. C., Yarh, J., Kuhn, A., Slater, A. M. \& Pascalils, O. (2002). Representation of the gender of human faces by infants: a preference for female. Perception, 31 , 1109-1021.

Simas, M. L. B. (1996). Contrasts thresholds at the blind spot: Effects of contralateral radial and angular frequencies. International Journal of Psychology, 31, 4843548435.

Simas, M. L. B. (2000). The multiple faces phenomenon: Some investigative studies. Perception, 29, 1393-1395.

Webster, M. A. \& MacLin, O. H. (1999). Figural aftereffects in the perception of faces. Psychonomic Bulletin \& Review, 6, 647-653.
Recebido: 09/04/2003

Última revisão: 08/01/2004

Aceite final: 22/01/2004

Maria Lúcia de Bustamante Simas é Doutora em Psicologia pela Queen's University, Ontario, Canada. Professora Adjunta do Departamento de Psicologia da Universidade Federal de Pernambuco. Coordenadora do Laboratório de Percepção Visual - LabVis. Bolsista do CNPq. Linha de Pesquisa: Percepção e Processamento Visual da Forma.

Natanael Antonio dos Santos é Doutor em Psicologia (Neurociências e Comportamento) pelo Instituto de Psicologia Experimental da Universidade de São Paulo. Professor Adjunto do Departamento de Psicologia da Universidade Federal da Paraíba. Coordenador do Laboratório de Processamento Visual - LabPVis. Linha de Pesquisa: Percepção e Processamento Visual da Forma em Humanos. 